\title{
Limited of Optimum Method for Separation Xylene Isomers by Gas Chromatography
}

\author{
Zainab Mahmood Abdala, Amel Naji Wadi, Zainab Shaye Hassan and Hadi kareem Dahaam \\ Central Directorate of the Laboratories, Ministry of Science and Technology, Baghdad-Iraq.
}

\begin{abstract}
The research includes the prepration of stationary phase of organic material from $10 \%$ Di Iso Nonyl Phthalate (DIP) and 5\% Di Nonyl Phthalate (DNP) for separation xylene isomers in petroleum derivatives by gas chromatography technique and for the purpose of designation optimal condition and determine the stationary phase selectivity by polar and polar materials separated and calculate the resolution degree for compared with columns chromatographic classic, Poly Ethylene Glycol (PEG) 20\% and capillary column (DP5) that separate on stationary phase column from preprate is the best record for the separation xylene isomers, and high resolution degree for meta and para xylene.
\end{abstract}

Keywords: Gas Chromatography, Xylene Isomers, Chromatographic of Separation Columns.

\section{Introduction}

Chromatography is one of the ways for physical separation of chemicals and appoint their concentration and quantities, as distributed materials to be separated between two phases: first phase, a stationary phase which passes through the second phase, a mobile phase and be the last carrier of the sample to be analyzed. In general, the process chromatographic occur as a result of the loops in and out repetitive material to be separated between the phases, and is the separation process is basically a succession of operations processed (or adsorption) in two phases and different Solubility of the material to be separated in each of the stationary phase and the mobile phase. Any difference in the result of $(\mathrm{K})$ Equilibrium Distribution of the material to be separated between the two phases [1]. Represents gas liquid chromatography (GLC) more threads chromatography sophisticated means separating the mixture through Partitioning or distributed between two phases, the first vapour moving phase and the second phase means residents are homogeneous (Stationary liquid phase) coated inert solid substrate (Intert solid support). This technique is used to separate the many of compounds, particularly organic compounds such as hydrocarbons and alcohols and esters, ketones, Aldehyde [2,3].

Using xylene widely as an intermediate in the manufacture of paints, pharmaceuticals, plastics, varnishes and as a solvent for paints, adhesives, detergents, pesticides and used as an intermediate in the production of acid, terephthalic and could produce material specifications desired in local markets [4]. The substances aromatic or aromatic economic value is considerable, due to be used as raw materials in the manufacture of many of the derivatives chemical task such as plastics, polymers and styrene and phenol fiber polyester resins used in manufacturing packaging materials, plastic bottles and textiles, as well as industry nylon, detergents and some petroleum solvents. These materials contain chemicals that are essential to the aromatic ring and one or more, and comes on top of these materials with the acrid smell of benzene, toluene and xylene (BTX) [5]. The isomers of xylene as the boiling point for ortho- xylene is $144.2{ }^{\circ} \mathrm{C}$ and melting is $-25.2^{\circ} \mathrm{C}$ either boiling the meta xylene are $139.1^{\circ} \mathrm{C}$ and the degree of melting is $-47.9^{\circ} \mathrm{C}$ and the boiling point of the Para xylene are $138.4^{\circ} \mathrm{C}$ and the degree of melting is $13.3^{\circ} \mathrm{C}$ [6]. Diisononyl Phthalate (DINP) C6H4(COOC9H19)2, is a clear, colorless, and almost odorless liquid chemical. It is soluble in most organic solvents. DINP is primarily used as a PVC plasticizer. is a general purpose plasticizer with a broad range of applications used in flexible PVC. It is widely used in the toy, construction, and general consumer product markets. It has limited use in food packaging and is not used in medical 
applications [7]. Note that the mobile phase is an inert nitrogen gas carrier the sample.

\section{The Aim of Research}

Preparation stationary phase used for the purposes of analysis chromatographic and it is useful separation xylene isomers in oil derivatives, and that it is necessary to determine the quality of designated product and determine the optimum conditions: Resolution, Tempreture degree, Flow rate and Selectivity of columns for the separation process and compare it with the conventional columns chromatography.

Materials and Methods of Work Standard compound

\begin{tabular}{|c||l||c||c||}
\hline No. & \multicolumn{1}{|c||}{ Compound } & Company & Purity \\
\hline \hline $\mathbf{1}$ & Ortho xylene & Fluka & $\mathbf{9 8 \%}$ \\
\hline \hline $\mathbf{2}$ & Para xylene & Fluka & $\mathbf{9 9 \%}$ \\
\hline \hline $\mathbf{3}$ & Meta xylene & BDH & $\mathbf{9 8 \%}$ \\
\hline \hline $\mathbf{4}$ & $\begin{array}{l}\text { Di Nonyl Phthalate } \\
\text { (DNP) }\end{array}$ & Fluka & $\mathbf{9 9 \%}$ \\
\hline \hline $\mathbf{5}$ & $\begin{array}{l}\text { Di Iso Nonyl } \\
\text { Phthalate (DIP) }\end{array}$ & $\begin{array}{l}\text { Riedel- } \\
\text { dehaen }\end{array}$ & $\mathbf{9 9 \%}$ \\
\hline \hline $\mathbf{6}$ & $\begin{array}{l}\text { Solid Support } \\
\text { (Chromosorb acidic } \\
\text { washed) W/ AW }\end{array}$ & Fluka & $\begin{array}{c}\mathbf{8 0}- \\
\mathbf{1 0 0}\end{array}$ \\
\hline 7 & Aceton & Fluka & $\mathbf{9 9 \%}$ \\
\hline
\end{tabular}

The devices used:

Gas Chromatography GC-9A of the Company Shemadzu detector FID as Fig.(1) and a Rotary evaporator type Buchi 461, Vacuum pump of the Company England.

\section{The preparation of the stationary phase}

Weight $0.5 \mathrm{gm}$ of Di Nonyl Phthalate with $1 \mathrm{gm}$ of material Di Iso Nonyl Phthalate with $8.5 \mathrm{gm}$ of solid supported to prepare the column 5\% Di Nonyl Phthalate and 10\% Di Iso Nonyl Phthalate, put materials in the beaker and $50 \mathrm{ml}$ of acetone as a solvent. Then put the mixture on the magnetic stirrer and were added solid supported slowly into the mix for blending perfectly with the continuance magnetic stirrer for 6 hours then was evaporating the solvent using a rotary evaporator and then leave the precpetated in the oven at a temperature $100^{\circ} \mathrm{C}$ for 3 hours to vapour the solvent.
The packing percentage $5 \%$ of the DNP and $10 \%$ of the DIP column glass has been packed column as follows: fill one end of the column, with amount of suitable material form glass wool and then connects this party from the column to the pump discharge machining, and begin to fillin the column prepared to material until the end of the column then placed Court of glass wool in the end.

Before conducting any test of the operating conditions of the column should be conditioning for two days or more, and are raising the temperature $\left(15-25^{\circ} \mathrm{C}\right)$ higher than the temperature for the analysis and to get rid of impurities and moisture and is linked to the column from the slot injection device. As for the other end and special detector hole is left in bulk and pass the carrier gas is to get rid of the impurities that may exist in the column without passing through the detector to ensure no contamination. 


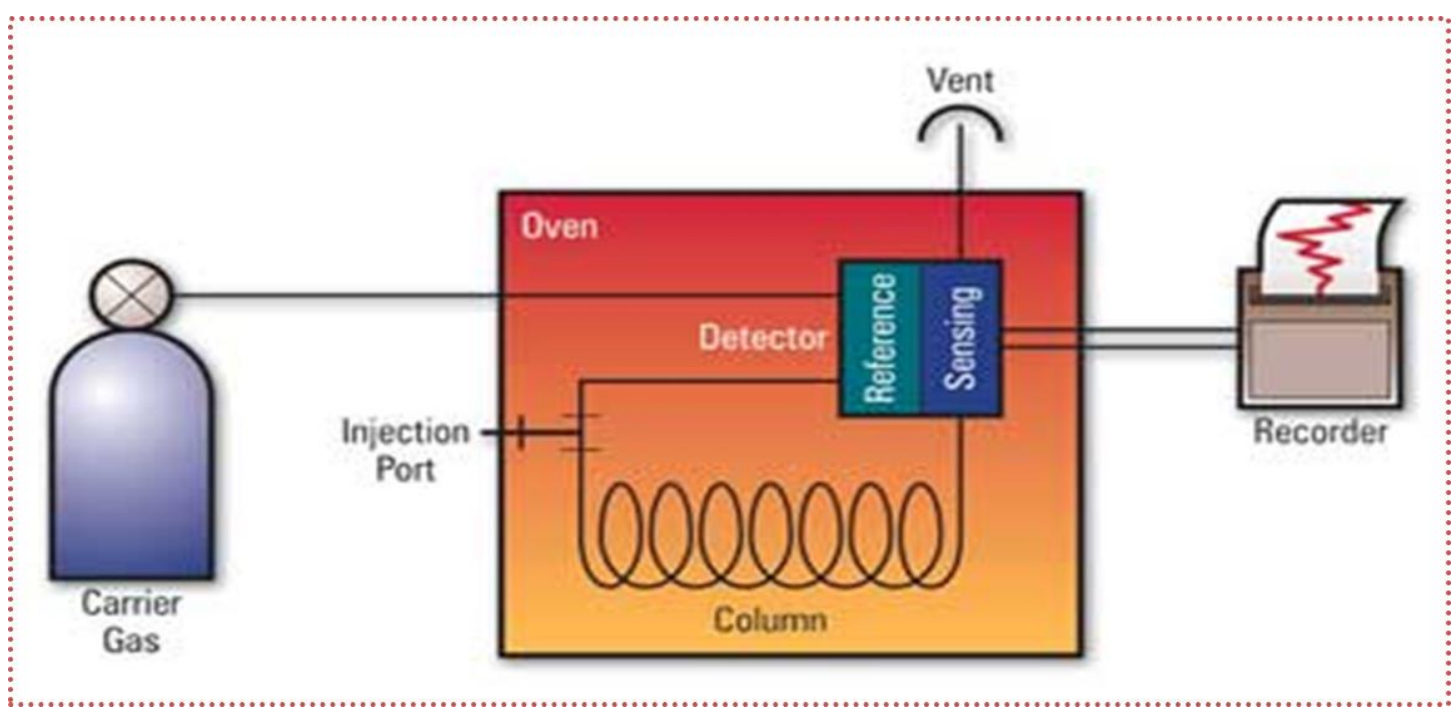

Fig.(1) Scheme of chromatography device.

\section{Results and Discussion}

It has been a chromatographic analysis of the xylene isomers on the following columns: column that contains the stationary phase Poly Ethylene Glycol (PEG) $20 \%$ and capillary column type (DP5) and the column containing the stationary phase prepared from 5\% DNP and $10 \%$ DIP as Table (1).

Table (1)

Type of Stationary Phase uses.

\begin{tabular}{|c|c|c|}
\hline General structure & Name & Polarity \\
\hline $\mathrm{HO}-\left(\mathrm{CH}_{2}-\mathrm{CH}_{2}-\mathrm{O}\right)_{\mathrm{n}}-\mathrm{H}$ & PEG & Polar \\
\hline $\begin{array}{c}\mathrm{CH}_{3}-\mathrm{Si}-\mathrm{Ph} \\
\mid \\
\end{array}$ & DP5 & $\begin{array}{l}\text { Modiraty } \\
\text { Polar }\end{array}$ \\
\hline $\begin{array}{c}\mathrm{OO} \\
\| \\
\mathrm{H}_{19} \mathrm{C}_{9}-\mathrm{O}-\mathrm{C}-\mathrm{Ph}-\mathrm{C}-\mathrm{O}- \\
\mathrm{C}_{9} \mathrm{H}_{19} \\
\end{array}$ & $\begin{array}{l}\text { DIP 10\% } \\
\text { DNP 5\% }\end{array}$ & $\begin{array}{l}\text { Non } \\
\text { Polar }\end{array}$ \\
\hline
\end{tabular}

Table (2)

The operating optimum conditions of the device are as follows.

\begin{tabular}{||l||c||}
\hline \multicolumn{1}{|c||}{ Detector } & FID \\
\hline \hline Carrier Gas & $\mathbf{N}_{2}$ \\
\hline Injector Temperature & $260^{\circ} \mathrm{C}$ \\
\hline \hline Initial Temperature & $\mathbf{1 2 0}^{\circ} \mathrm{C}$ \\
\hline \hline Final Temperature & $250^{\circ} \mathrm{C}$ \\
\hline Initial Time & $1 \mathrm{~min}$ \\
\hline \hline Final Time & $15 \mathrm{~min}$ \\
\hline \hline Rate & $\mathbf{2}^{\circ} \mathrm{C} / \mathrm{min}$ \\
\hline Volum injaction & $1 \mu$ \\
\hline \hline Carrier Gas Flow Rate & $30 \mathrm{ml} / \mathrm{min}$ \\
\hline
\end{tabular}

\begin{tabular}{|l||l|}
\hline $\begin{array}{l}\text { Pressure Across the } \\
\text { Column }\end{array}$ & $1.6 \mathrm{Kg} / \mathrm{cm}^{2}$ \\
\hline
\end{tabular}

Selectivity dependent on the type of stationary phase separation process, which it used so it is important to choose the sutible stationary phase mixture to be separated both in terms of achieving a better separation within (the high value for $\mathrm{R}$ ) in shorter period of analysis.

The separation takes place in the column by physico-chemical interaction of the sample compounds with the stationary and the mobile phases. The separation depends on stationary phase type. The selectivity is influenced by polarizability, solubility, magnitude of dipoles and hydrogen bonding behavior of the stationary phase with the different compounds [8].

The stationary phase determines the ability of the column to separate sample components. If the stationary phase retains one compound to a greater extent than another, the compounds can be separated. The selection of the stationary phase is based on the following chemical principle: a non polar column is better for separation of non polar analytes [9].

The polarity of the stationary phase is determined by the structure of the polymer which constitutes the stationary phase. A non polar column (stationary phase: e.g. DNP 5\% and DIP 10\%) separates the analytes regarding to their boiling points and their different vapor pressure [10].

Showed Fig.(2) Chromatogram return to separation of xylene isomers on column 
Polyethyleneglycol (PEG 20\%) appearance two peaks integration return to meta and para xylene in retention time 1.735 min and appear peak return to ortho xylen in retention time $3.272 \mathrm{~min}$, the separation is bad becuse the polarity of the stationary phase increases. High polar stationary phases are based on polyethylene glycols. In this case, the separation takes place due to the polarity and the boiling points of the compounds [11], to calculated the resolution degree $(\mathrm{R})$ for meta xylene and para xylene:

$R=\frac{2(\mathrm{tR} 2-\mathrm{tR} 1)}{(\mathrm{W} 1+\mathrm{W} 2)}$

$\mathrm{R}$ : resolution degree for two peak successive. $t_{R 2}, t_{R 1}$ : retention time of the first and second peak.

$\mathrm{W}_{1}, \mathrm{~W}_{2}$ : wideth of the first and second peak.

$R=\frac{2(1.735-1.735) \mathrm{min}}{(0.1+0.1) \mathrm{cm}}$

$R=0 \min / \mathrm{cm}$

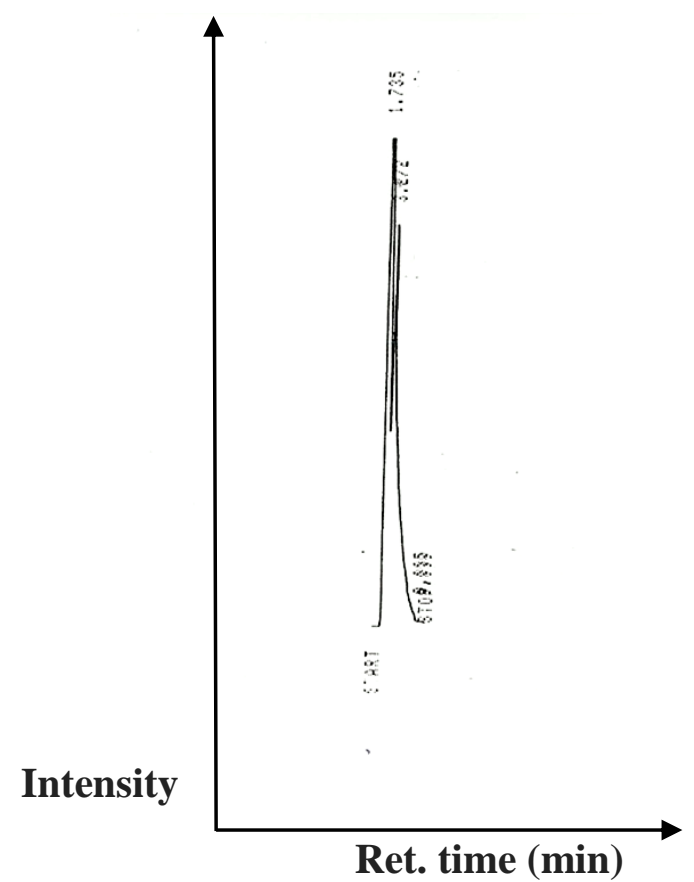

Fig.(2) Represents Chromatogram for separation of xylene isomers on a column PEG 20\%.

Showed Fig.(3) Chromatogram return to separation of xylen isomers on a capillary column DP5 the same conditions of the separation device as Table (2), appear peak return to p-xylen in retention time $0.586 \mathrm{~min}$ and peak return to $\mathrm{m}$-xylen in retention time $0.702 \mathrm{~min}$, the sepration is not completely but it is best of PEG column because the capillary column modiraty polar, appear peak return to o-xylen in retention time $2.925 \mathrm{~min}$, For calculated the resolution degree( $R)$.

$R=\frac{2(0.702-0.586) \mathrm{min}}{(0.1+0.3) \mathrm{cm}}$

$R=0.58 \mathrm{~min} / \mathrm{cm}$

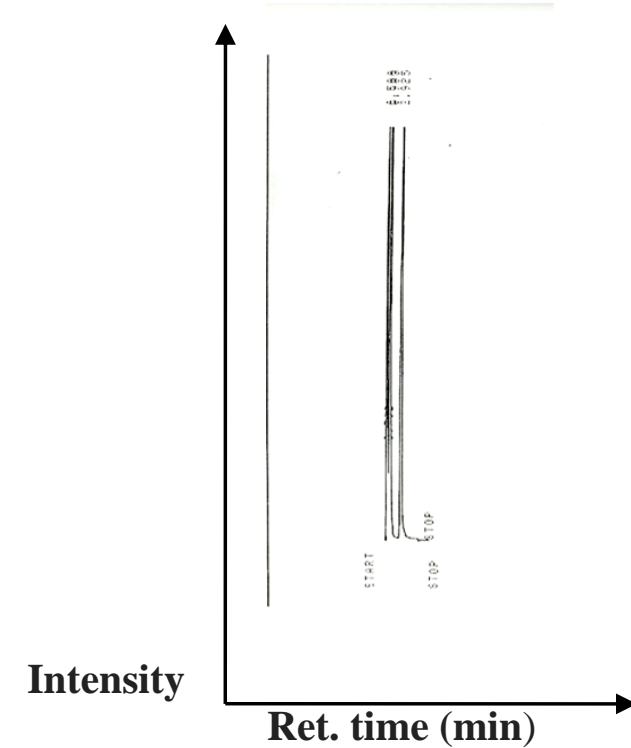

Fig.(3) Chromatogram of the separation of xylene isomers on a column DP5.

Showed Fig.(4) Chromatogram return to separation of xylene isomers on a column DNP 5\% and DIP 10\%, the same conditions of the separation device as Table (2), appear peak return to p-xylene in retention time $3.023 \mathrm{~min}$ and peak return to $\mathrm{m}$-xylene in retention time $4.145 \mathrm{~min}$ the sepration is completely it best from PEG column and capillary column DP5 because the column DNP 5\% and DIP 10\%. is non polar, appear peak return to o-xylene in retention time $6.312 \mathrm{~min}$, For calculated the resolution degree $(\mathrm{R})$.

$$
\begin{aligned}
& R=\frac{2(4.145-3.023) \mathrm{min}}{(0.3+0.3) \mathrm{cm}} \\
& R=3.74 \mathrm{~min} / \mathrm{cm}
\end{aligned}
$$




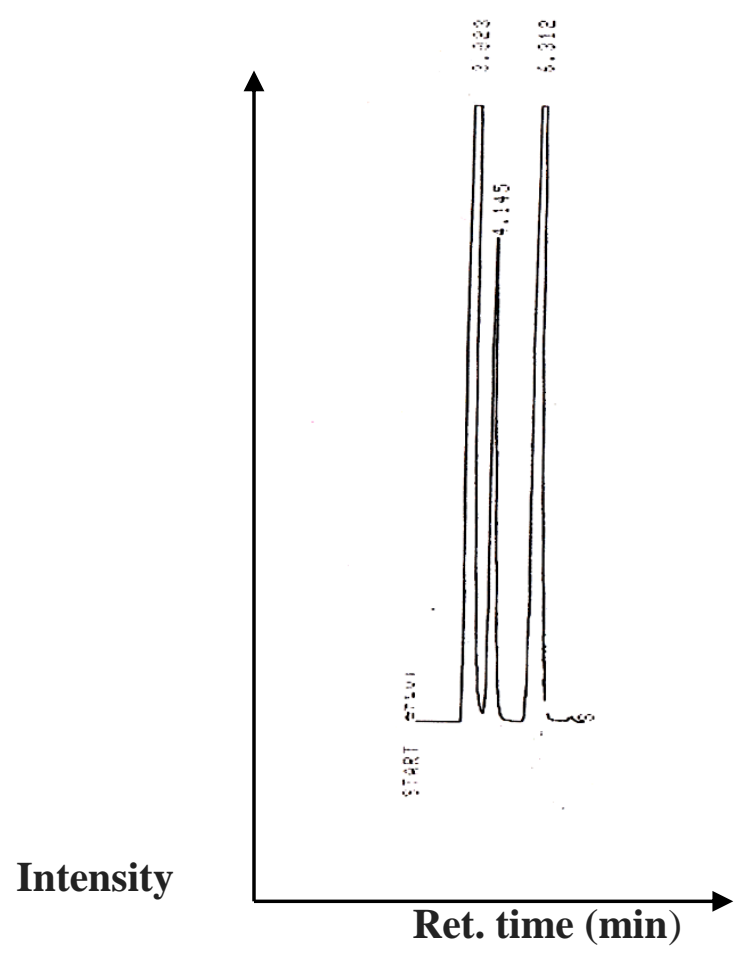

Fig.(4) Represents Chromatogram for the separation of xylene isomers on a column DNP 5\% and DIP $10 \%$.

\section{References}

[1] Cody R. B., Laramee J. A., "Versatile new ion source for the analysis of materials in open air under ambient conditions". Anal. Chem., V.77, P. 2297-2302. 2005.

[2] Belaidi D., Sebih S., Bouda S., Guermouche M. H., Bayle J. P., "Comparison of two liquid crystals as stationary phases in capillary gas chromatography" J.Chromatogr. A. V.1087, P.52. 2005.

[3] Hsieh Y., Korfmacher W.A., "Systems for Drug Metabolism, Pharmacokinetic Screening and Current Drug Metabolism". Current Drug Metabolism .V. 7, No.5, P. 479-489. 2006.

[4] Apte A. and Meitei N. S., "Bioinformatics in Glycomics: Glycan Characterization with Mass Spectrometric Data Using SimGlycan". Methods in molecular biology. Methods in Molecular Biology. V. 600, P. 269-281. 2009.

[5] Hoffman J., Chaney R., Hammack H., "Phoenix Mars Mission The Thermal Evolved Gas Analyzer". Journal of the American Society for Mass Spectrometry, V. 19, No. 10, P. 1377-83. 2008.
[6] Blow A., Nathan, "Glycobiology: A spoonful of sugar". Nature., V. 457, No. 7229, P. 617-620. 2009.

[7] Koch H. M., Angerer J., "Di-iso nonylphthalate (DINP) metabolites in human urine after a single oral dose of deuterium - labeled DINP" .Int .J. Hyg. Environ. Health., V. 210, No. 1, P. 9-19. 2007.

[8] Petrie S., Bohme D. K., "Ions in space". Mass Spectrometry Reviews.V. 26, No. 2, PP. 258-280. 2007.

[9] Harvey D., Dwek R. A., Rudd P.M., "Determining the Structure of Glycan Moieties by Mass Spectrometry". Current Protocols in Protein Science. Chapter 12.12.7-12.7.15. 2000.

[10] Xiao-min X., Yi-ping R., Zeng-xuan C., Jian-long H., Bai-fen H., "Direct determination of melamine in dairy products by gas chromatography/mass spectrometry with coupled column separation", Analytica Chimica Acta. V. 650, P. 39-43. 2009.

[11] Hernández-Hernández O., Calvillo I., Lebrón-Aguilar R., Moreno F. J., Determination of ochratoxins in nuts and grain samples by in-tube solid-phase microextraction coupled with liquid chromatography-mass spectrometry" , Journal of Chromatography A. V. 1220, P. 57- 67. 2012.

الخلاصة

Di تضمن البحث تحضير طور ثنابت من مادة عضوية

Di Iso (DIP), 5\% Nonyl Phthalate (DNP) 10\% Nonyl Phthalate الموجودة في المشتقات النفطية بتقنية كروماتوغرافيا الغاز لغرض تعبين تراكيزها وتحديد الظروف المنلى للفصل وتحديد الاختيارية للطور الساكن حسب القطبية وقطبية المواد المفصولة عليه وحساب درجة الفصل ومقارنتها مع بقية Poly Ethylene Glycol الاعمدة الكروماتوغرافية التقليدية دمعان Capillary ( بنسبة تحميل 20\% وعمود شعري (PEG) column(DP5 المحضر هو افضل فصل لايزومرات الزايلين واعلى درجة فصل لـ ميتا و بارا زايلين. الين. 